Hoang TH. Prevalence and causes of blindness in children in Vietnam. Ophthalmology. 2012 Feb; 119(2):355-61.

4. Muñoz B, West SK, Rubin GS, et al. Causes of blindness and visual impairment in a population of older Americans: the Salisbury Eye Evaluation Study. Arch Ophthalmol. 2000; 118(6):819-825.

5. Ngguê̂n Thị Thu Hiền, Nguyển Xuân Hiệp. ứng dụng phương pháp phuc hồi chức năng thị giác trên những người khiếm thị trưởng thành. Tạp chí Y học Việt nam. 2014; 417: 85-88.

6. Sapkota K, Kim DH. Causes of low vision and major low-vision devices prescribed in the lowvision clinic of Nepal Eye Hospital, Nepal. Anim Cells Syst (Seoul). 2017; 21(3):147-151.

7. Tôn Thị Kim Thanh, Nguyễn Thị Thu Hiền. Nghiên cứu ứng dụng môt sô dung cu trợ thi trên trẻ khiếm thị. Tạp chí nhãn khoa Việt nam. 2007; 9:45-54.

8. Vijaya $L$, George $R$, Asokan $R$, Velumuri $L$, Ramesh SV. Prevalence and causes of low vision and blindness in an urban population: The Chennai Glaucoma Study. Indian J Ophthalmol. 2014; 62(4):477-481.

\title{
ĐĂC ĐIỂM CÂN LÂM SÀNG CỦA BÊ̂NH NHÂN PHẪU THUẬT SỎI TIẾT NIỆU TẠI BỆNH VIỆN ĐA KHOA ĐỨC GIANG
}

\section{TÓM TẮT}

Mục tiêu: Mô tả đặc điểm cận lâm sàng của nhóm bênh nhhân sỏi tiết niêuu phải phấu thuật từ đó đưa một sổ kiến nghị về chỉ định xét nghiệm vi sinh. Phương pháp: nghiên cứu hồi cứu 56 bệnh nhân phẫu thuât sỏi tiết niệu tại bệnh viện đa khoa Đức Giang có xét nghiệm nuôi cấy tìm vi sinh vật từ tháng 9/2019 đến tháng 9/2020. Kết quả: Trong 56 bệnh nhân phấu thuật sỏi tiết niệu thì có $44,6 \%$ bênh nhân có tăng bạch cầu trong máu ngoại vi. Có $71,4 \%$ bệnh nhân có giãn đài bể thận. Có 54 bệnh nhân được nuôi cấy nước tiểu thì có $11,1 \%$ bênh nhân được xác định là dương tính (Escherichia Coli, Acinetobacter Baumannii, Klebsiella Pneumoniae, staphylococcus capitis). Có 13 bệnh nhân được cấy máu chiếm 23,2\% trong đó dương tính có 5 ca (Escherichia Coli, Staphylococcus saprophyticus, Candida albicans). Kết luận: Tỷ lệ nuôi cây phát hiên vi sinh vật là rất thấp nền đối với nhóm bệnh nhân sỏi tiết niệu phải phẫu thuật thì không nhất thiết phải làm xét nghiệm nuôi cấy thường quy. niệu

Tư khóa: Phẫu thuật sỏi tiết niệu, vi sinh vật tiết

\section{SUMMARY}

SUBCLINICAL CHARACTERISTICS OF PATIENS WITH URINARY STONE SURGERY AT DUC GIANG GENERAL HOSPITAL

Objective: to characterize some subclinical features of urinary stone patients requiring surgery, thereby giving some recommendations for microbiological testing. Method: Retrospective study of 56 urinary stone surgery patients at Duc Giang General Hospital with microbiological culture tests from September 2019 to September 2020. Result: In 56 patients with urinary stone surgery, $44.6 \%$ of patients had leukocytosis in peripheral blood.

${ }^{1}$ Bệnh viện đa khoa Đức Giang

Chịu trách nhiệm chính: Đố Minh Trí

Email: dominhtri37@yahoo.com.vn

Ngày nhận bài: 15.12.2020

Ngày phản biên khoa hoc: 25.01.2021

Ngày duyệt bài: 9.2.2021
Percentage of patients with pyeloderma was $71.4 \%$. In 54 patients with urine sample, $11.1 \%$ of the patients were confirmed positive (including Escherichia Coli, Acinetobacter Baumannii, Klebsiella Pneumoniae, staphylococcus capitis). Five patients were postive blood samples among $23.2 \%$ did microorganism culture ((Escherichia Coli, Staphylococcus saprophyticus, Candida albicans). Conclusion: The incidence of culture for detection of microorganisms was very low, so it is not necessary to do routine culture tests for urinary stone patients.

\section{I. ĐẶT VẤN ĐỀ}

Sỏi tiết niệu là chất khoáng nằm trong hệ tiết niệu, theo báo cáo gần đây của 7 quốc gia thì tỷ lệ hiện mắc sỏi tiết niệu là $7-14,8 \%$, và ở hầu hết các quốc gia [1]. S̉oi hay kết hợp với nhiễm trùng tiết niệu do gây tắc nghẽn đường bài tiết vi khuẩn sẽ ứ đọng, tập trung và từ đó có thể gây viêm, nhiễm khuẩn tại chố ngược dòng lên phía trên [2]. Ngược lại nhiễm trùng tiết niệu cũng làm bệnh nhân dễ hình thành sỏi [3]. Nhiểm trùng đặc hiệu do vi khuẩn đặc biệt gây nên như lao, lậu, nấm ... Nhiễm trùng không đặc hiệu do vi khuẩn gram (-) hay gram (+) [2]. Cẩu hỏi đặt ra là có cần thiết phải làm xét nghiệm vi sinh trong các bệnh nhân sỏi tiết niệu phải phẫu thuật hay không?. Để xác định được vi khuẩn thì bệnh viện phải có phòng xét nghiệm vi sinh, nuôi cẩy được vi khuẩn và thực hiện được kỹ thuật kháng sinh đồ. Trang bị này không phải bệnh viện nào cũng có.

\section{II. ĐỐl TƯỢNG VÀ PHƯƠNG PHÁP NGHIÊN CỨU}

2.1. Đối tượng nghiên cứu: Tổng số 56 bệnh nhân được phầu thuật sỏi tiết niệu tại bệnh viện đa khoa Đức Giang có xét nghiệm nuôi cấy máu hoặc nước tiểu tìm vi sinh vật trước mổ hoặc trong mổ.

2.2. Phương pháp nghiên cứu 
2.2.1. Thiết kế nghiên cứu: nghiên cứu mô tả cắt ngang.

2.2.2. Cỡ mẫu và chọn mẫu:

- Tiêu chuẩn lựa chọn:

+ Bệnh nhân phẫu thuật sỏi tiết niệu tại BVĐK Đức Giang từ 9/2019 - 9/2020

+ Bệnh án có xét nghiệm nuôi cấy tìm vi sinh vật (Bệnh phẩm là máu hoặc nước tiểu được lấy trước hoặc trong khi mổ)

+ Có hồ sơ bệnh án đây đủ.

Tiêu chuẩn loại trừ:

+ Bệnh nhân có phẫu thuật hệ tiết niệu nhưng không do sỏi

+ Bệnh phẩm nuôi cấy tìm vi sinh được lấy sau khi mổ xong

+ Bệnh nhân hồ sơ không đầy đủ.

2.2.3. Thời gian và địa điểm nghiên cứu

- Thời gian nghiên cứu: Từ tháng 9/2019 đến tháng 9/2020

- Địa điểm nghiên cứu: Khoa ngoại thận tiết niệu bềnh viện đa khoa Đức Giang

2.2.4. Công cụ và phương pháp thu thập số liệu

- Thu thập tất cả bệnh nhân có xét nghiệm nuôi cây vi sinh vật (nuôi cấy máu hoặc nước tiểu) của khoa Ngoại thận tiết niệu sau đó chọn lựa bệnh án có phẫu thuật do sỏi tiết niệu (xem cách thức mổ), chọn lựa bệnh án có xét nghiệm nuôi cây máu hoặc nước tiểu trước, trong mổ.

- Bệnh nhân có ít nhất một trong 3 kết quả chụp UIIV, siêu âm hoặc chụp cắt lớp vi tính (chụp $\mathrm{CT}$ ) có giãn đài bể thận thì được cho là giãn đài bể thận.

- Giá trị bạch câu tăng khi > $10.000 \mathrm{G} / \mathrm{L}$

- Chỉ định nuôi cấy vi sinh do bác sĩ lâm sàng chỉ định khi nghi ngờ có nhiễm khuẩn tiết niệu (đau thắt lưng, đau mạn sườn, tiểu buốt, có hình ảnh giãn đài bể thận) hoặc nghi nhiếm trùng máu như sốt cao, rét run ...

- Bảo quản chuyên chở mẫu và nuôi cấy theo quy trình đã duyệt

2.3. Xử lý số liệu: Số liệu được thu thập và xử lý bằng phần mềm Stata 14.0. Thống kề mô tả được áp dụng để trình bày các tần suất và tỷ lệ \%.

2.4. Đạo đức trong nghiên cứu: Nghiên cứu này được sự đồng ý của Ban lãnh đạo BVĐK Đức Giang trước khi tiến hành nghiên cứu. Tất cả các thông tin của bệnh nhân chỉ được sử dụng cho mục đích nghiên cứu.

\section{KẾT QUẢ NGHIÊN CỨU}

Tổng số 56 bênh nhân đủ điều kiênn đưa vào nghiên cứu trong đó nữ chiếm $60,7 \%$, nam chiếm 39,3\%. Tuổi trung bình $55,7 \pm 14,2$ tuổi thấp nhất là 19, tuổi cao nhất là 80 .
Bảng 1: Kêt quả xét nghiệm bạch câu

\begin{tabular}{|c|c|c|}
\hline Bạch câu & $\begin{array}{c}\text { Số bệnh } \\
\text { nhân (n) }\end{array}$ & $\begin{array}{c}\text { Tỹ lệ } \\
\text { (\%) }\end{array}$ \\
\hline Số lượng bình thường & 31 & 55,4 \\
\hline Số lượng bạch cầu cao & 25 & 44,6 \\
\hline Tống & $\mathbf{5 6}$ & $\mathbf{1 0 0}$ \\
\hline
\end{tabular}

Tất cả bệnh nhân được xét nghiệm máu trước mổ thì chỉ có 44,6 \% bệnh nhân có số lượng bạch cầu tăng.

Bảng 2: Tình trạng giãn đài bể thận

\begin{tabular}{|c|c|c|}
\hline $\begin{array}{c}\text { Giãn đài bể } \\
\text { thận }\end{array}$ & $\begin{array}{c}\text { Số bệnh } \\
\text { nhân (n) }\end{array}$ & Tỷ lệ (\%) \\
\hline Có giãn & 40 & 71,4 \\
\hline Không giãn & 16 & 28,6 \\
\hline Tống & $\mathbf{5 6}$ & $\mathbf{1 0 0}$ \\
\hline
\end{tabular}

Có 71,4\% trường hợp được phát hiện giãn đài bể thận qua chẩn đoán hình ảnh bằng siêu âm, X - quang hoặc chụp CT

Bảng 3: Cấy nước tiểu trước và trong mổ

\begin{tabular}{|c|c|c|}
\hline $\begin{array}{c}\text { Cây nước } \\
\text { tiểu }\end{array}$ & $\begin{array}{c}\text { Số bệ̂nh } \\
\text { nhân (n) }\end{array}$ & Tỷ lệ (\%) \\
\hline Âm tính & 48 & 88,9 \\
\hline Dương tính & 6 & 11,1 \\
\hline Tổng & $\mathbf{5 4}$ & $\mathbf{1 0 0}$ \\
\hline
\end{tabular}

Trong 54 trường hợp cấy nước tiểu thì có $11,1 \%$ có kết quả dương tính với vi khuẩn. Vi khuẩn phân lập được là: Escherichia Coli, Acinetobacter Baumannii, Klebsiella Pneumoniae, Staphylococcus capitis.

\section{Bảng 4: Cây máu trước mồ}

\begin{tabular}{|c|c|c|c|}
\hline Cấy máu & \multicolumn{2}{|c|}{ Số bệnh nhân (n) } & Tỷ lệ(\%) \\
\hline Có cấy máu & \multirow{2}{*}{13} & Dương tính (5) & \multirow{2}{*}{23,2} \\
\cline { 3 - 4 } & & Âm tính (8) & \\
\hline Không cấy máu & \multicolumn{2}{|c|}{43} & 76,8 \\
\hline Tống & $\mathbf{5 6}$ & & $\mathbf{1 0 0}$ \\
\hline
\end{tabular}

Cấy máu có $13 / 56$ bênh nhân chiếm 23,2\% trong đó dương tính vi sinh vật có $5 \mathrm{ca}$.

Vi sinh vật phân lập được là: Escherichia Coli, Staphylococcus saprophyticus,

Candida albicans.

\section{BÀN LUÂ̂N}

Đặc điểm cận lâm sàng của đối tượng nghiền cứu. Vể xét nghiệm bạch cầu chỉ có $44,6 \%$ bệnh nhân có số lượng bach cầu tăng. Khi bạch cầu tăng thường có ý nghĩa là bệnh nhân đang bị viêm nhiễm, đây là phản ứng của cơ thể trước tình trạng viêm nhiểm, tuy nhiên cũng có trường hợp mặc dù bệnh nhân có viêm nhiểm nhưng bạch cầu không tăng gặp trong bệnh nhân nhiều tuổi, đáp ứng miễn dịch kém. Tương tự nghiên cứu tại Bệnh viện đa khoa Thành phố Vinh có 46 bểnh nhân chiếm (43\%) có xét nghiệm bạch cầu tăng trong nhóm 107 
bệnh nhân có sỏi tiết niệu đến khám và điều trị tại bệnh viện [4].

Tình trạng giãn đài bể thận là do viên sỏi gây ứ trệ đường bài tiết, trong nghiên cứu có 40 trường hợp chiếm $71,4 \%$ có giãn đài bể thận. Siêu âm và X-quang bụng thường là 2 phương tiện thường quy thông dụng, dễ thực hiện để chẩn đoán sỏi hệ tiết niệu. Tuy nhiên siêu ẩm có độ nhạy cao hơn X-quang khoảng từ $7-13 \%$ và đặc hiệu hơn X-quang từ 10-14\%[1]. Chụp CT xác định các tổn thương như chụp Xquang thận thường, UIV nhưng ở mức độ chính xác hơn.

Chụp cắt lớp vi tính là kỹ thuật đòi hỏi trang bị máy móc đắt tiền, bệnh nhân chụp cắt lớp cũng bị ảnh hưởng bởi tia xạ nhiều hơn, nên cần cân nhắc kỹ khi chỉ định chụp. Thường những trường hợp khó như sỏi nhỏ, có tình trạng giãn đường bài xuất mà trên siêu âm và Xquang thông thường không lý giải chắc chắn thì nên chup CT.

Kết quả xét nghiệm vi sinh vật. Trong nghiên cứu có 54 trường hợp được cấy nước tiểu thì phát thiện có 6 trường hợp dương tính và 11 trường hợp được cấy máu thì phát hiện có 5 trường hợp dương tính. Trong 5 trường hợp cấy máu dương tính thì có 1 trường hợp cấy nước tiểu cũng dương tính. Nhiễm khuẩn tiết niệu có thể gây nhiễm khuẩn huyết và nhiễm khuẩn huyết có thể gây nhiễm khuẩn tiết niệu, vì số ca nuôi cấy máu và nước tiểu dương tính ít nên chúng tôi không tính mối liên quan của tình trạng nuôi cấy máu và nước tiểu để đi sâu phân tích nguyên nhân nào có trước và nguyên nhân nào có sau. Theo nghiên cứu của Hoàng Thị An Hà có 136 bệnh nhân sỏi tiết niệu khi nuôi cãy nước tiểu có 30 ca dương tính chiếm 22\%[4]. Nghiên cứu của chúng tôi là hồi cứu, bệnh nhân lấy nước tiểu khi vào viện và có bệnh nhân lấy nước tiểu trong mổ sau khi lấy sỏi (nước tiểu trên sỏi) nhưng trong hồ sơ không thể hiện rõ là bệnh nhân có sử dụng kháng sinh trước khi vào viện hay không, nên tỷ lệ nuôi cây tìm vi sinh vật trong nghiên cứu của chúng tôi thấp $(11,1 \%)$. Kết quả này gợi ý cần tiếp tục nghiên cứu trên số lượng mâuu lớn hơn hoặc thời gian nhiều hơn.

Cấy nước tiểu tìm được 4 loại vi khuẩn, cấy máu tìm được 2 loại vi khuẩn và 1 loại nấm. Vi khuẩn phân lập được từ nuôi cây nước tiểu tương quan với vi khuẩn nuôi cấy từ sỏi niệu có độ nhạy là $90 \%$, độ đặc hiệu là $79,69 \%$ [1].

Vi khuẩn phân lập được từ nuôi cấy nước tiểu phổ biến nhất là Escherchia coli $(46,7 \%)$, tiếp theo là Klebsiella pneumonia $(16,7 \%)$ và Proteus mirabilis $(13,3 \%)$ từ cây nước tiểu và sỏi $[1]$.
Cũng trong nghiên cứu của Yao Bai (Trung Quốc) khi cấy nước tiểu giữa dòng để phân tích mầm bênh kết quả chủng gram âm chiếm $75,2 \%$ trong đó Escherichia coli là vi khuẩn gây bệnh thường xuyên được phân lập tổng thể và là trực khuẩn Gram âm thường xuyên được phân lập nhất. Cầu khuẩn gram dương chiếm $24,8 \%$ và trong đó Enterococcus faecalis là loài cầu khuẩn Gram dương được phân lập thường xuyên nhất [5].

Trong nghiên cứu của chúng tôi tuy số bệnh nhân nuôi cấy xác định vi khuẩn ít nhưng đều là những vi khuẩn thường hay gặp được báo cáo. Tác nhân gây bệnh phổ biến nhất cho cả nhiễm trùng tiểu không biến chứng và phức tạp là Escherichia coli [6].

Đối với các tác nhân liên quan đến nhiễm trùng tiểu không biến chứng, được theo sau với tỷ lệ phổ biến là Klebsiella pneumoniae, Staphylococcus saprophyticus, Enterococcus faecalis, Streptococcus nhóm B (GBS), Proteus mirabilis, Pseudomonas aeruginosa, Staphylococcus aureus và Candida [6].

\section{KẾT LUÂN}

Tỷ lệ bệnh nhân sỏi thận phải phẫu thuật tại bệnh viện Đa khoa Đức Giang có nuôi cấy phát hiện vi khuẩn dương tính trong nước tiểu chiếm $11,1 \%$; vi khuẩn tìm thây trong nước tiểu là Escherichia Coli; Acinetobacter Baumannii; Klebsiella Pneumoniae

Số bệnh nhân được chỉ định nuôi cấy máu tìm vi sinh vật là $13 / 56(23,2 \%)$ trong đó kết quả nuôi cấy dương tính $5 / 13$ bệnh nhân. Vi sinh vật tìm được là Escherichia Coli; Staphylococcus saprophyticus và nấm Candida albicans.

\section{KHUYẾN NGH!}

Về chỉ định xét nghiệm nuôi cấy tìm vi sinh vật: do tỷ lệ nuôi cấy tìm được sự hiện diện của vi sinh vật trong nước tiểu là rất thấp nên không nhất thiết đưa xét nghiệm này vào xét nghiệm thường quy.

\section{TÀl LIẸU THAM KHẢO}

1. Khan, S.R., et al., Kidney stones. Nature reviewș. Disease primers, 2016. 2: p. 16008-16008.

2. Nguyển Kỳ, Nhiễm khuẩn tiết niệu - Sử dụng kháng sinh in Bệnh học tiết niệu. 2007, Hội tiết niệu - Thận học Việt Nam, Nhà xuất bản Y học. p. tr. 226-237.

3. Golan, R., K.L. Cooper, and O. Shah, Management of Small, Non-obstructing Renal Stones in Adults With Recurrent Urinary Tract Infections. Reviews in urology ${ }_{2}$ 2020. 22(2): p. 52-56.

4. Hoàng Thị An Hà, Nguyến Thanh Hải và cs, nghiên cứu đặc điểm nhiếm khuẩn tiết niệu trên bệnh nhân sỏi tiết niệu tại bệnh viện đa khoa Thành phố Vinh - Nghệ An. Tạp chí KH-CÑ Nghệ An, 2018. 
5. Bai, Y., et al., Analysis of Urinary Pathogen Cultures and Drug Sensitivity in Patients with Urinary Stones for Five Consecutive Years in Xiangya Hospital, China. Infection and drug resistance, 2020. 13: p. 1357-1363.
6. Flores-Mireles, A.L., et al., Urinary tract infections: epidemiology, mechanisms of infection and treatment options. Nature reviews. Microbiology, 2015. 13(5): p. 269-284.

\section{ĐÁNH GIÁ Độ PHÙ HỢP GIỮA KẾT QUẢ MÔ BÊNNH HỌC VÀ ĐĂC ĐIỂM NộI SOI TRONG CHẨN ĐOÁN BỆNH VIÊM RUộT MẠN TÍNH}

\section{TÓM TẮT}

Đặt vấn đề: Viêm ruột mạn tính (IBD) là bệnh lý có cơ chế bênh sinh phức tap và đang có xu hướng tăng lên trên thế giới. Chẩn đoán cần có sự phối hợp đăc điểm lâm sàng, kết quả nội soi và hình thái mô bệnh học $(\mathrm{MBH})$ đặc biệt trong những trường hợp không điển hình. Nghiên cứunày được thực hiện với mục tiêu khảo sát độ phù hợp trong chẩn đoán IBD giữa kết quả $\mathrm{MBH}$ và hình ảnh nội soi. Phương pháp nghiên cứu: Nghiên cứu hồi cứu mô tả được thực hiện tại Bệnh viện Đại Học Y Hà Nội từ tháng 2/202010/2020trên bệnh nhân có kết quả nội soi theo dõi viêm loét đai trực tràng chảy máu (VLĐTTCM) hoặc Crohn và đối chiếu với kết quả $\mathrm{MBH}$. Các tiêu bản sau đó được đọc độc lập lần 2 bởi chuyên gia giải phẫu bênh về IBD, sau đó đối chiếu lai với kết quả lần 1 và hình ảnh nội soi. Kết quả nghiên cứu: Có 46 bệnh nhân thỏa mãn tiêu chuẩn lựa chọn, tuổi trung bình 44,23(14,5), min max 19-74, tỷ lệ nữ/nam là 1,3.Trên nội soi, $89,1 \%$ các bệnh nhân được chẩn đoán là VLĐTTCM, chỉ có 5 bệnh nhân là Crohn (10,9\%). Mức độ đồng thuân giữa kết quả nội soi và $\mathrm{MBH}$ lần 1 và lần 2 ở mức thấp và trung bình với hệ số $\mathrm{k}$ tương ứng là 0,265 và 0,491 . Mức đô đồng thuân của kết quả $\mathrm{MBH} 2$ lần ở mức trung bình $(\mathrm{k}=0,487)$. Kết luận: Nghiên cứu ghi nhận mức độ đồng thuận giữa kết quả nội soi và $\mathrm{MBH}$ cũng như giữa hai lần chẩn đoán $\mathrm{MBH}$ có ý kiến của chuyên gia đều ở mức thấp và trung bình $(\kappa<0,6)$.

Tư khoá: viêm ruột mạn tính, mô bệnh học, kết quả nội soi.

\section{SUMMARY \\ EVALUATION OF AGREEMENT BETWEEN ENDOSCOPIC AND HISTOPATHOLOGY RESULTS FOR THE DIAGNOSIS OF INFLAMMATORY BOWEL DISEASE}

\footnotetext{
${ }^{1}$ Trường Đại học Y Hà Nôi

Bênh viên Đại hoc Y Hà Nôi

${ }^{3}$ Viện nghiên cúu và đào tạo Tiêu hoá, gan mạt

${ }^{4}$ Trướng Đai hoc Y dước, Đại hoc Quốc gia Hà Nội

Chịu trách nhiệm chính: Đào Việt Hằng

Email: daoviethang@hmu.edu.vn

Ngày nhận bài: 14.12.2020

Ngày phản biên khoa hoc: 25.01.2021

Ngày duyệt bài: 10.2.2021
}

\section{Đào Việt Hằng ${ }^{1,2,3}$, Vũ Việt Sơn ${ }^{2}$, Trần Thị Thu Trang ${ }^{3,4}$, Đào Thị Luận ${ }^{1,2}$}

Introduction: Inflammatory bowel disease (IBD) is a disease with complicating pathophysiology and increasing prevalence worldwide. Diagnosis of IBD, especially in atypical cases, is based on the combination of clinical symptoms, endoscopic and histopathology results. Our study aimed to evaluate the level of agreement on the diagnosis of IBD between endoscopic and histopathology results. Methods: a descriptive retrospective study was conducted at Hanoi Medical University Hospital from February 2020 to October 2020 in patients who had endoscopy images suspected of ulcerative colistis (UC) or Crohn's diseases and had histopathology reports. The biopsy samples were examined independently by a histopathologist specialized in IBD in second round; the expert's reports were compared with the first reports and the endoscopic results. Results: 46 patients met the selection criteria, the mean age was 44.23 (14.5), min-max was $19-74$, the female/male ratio was 1.3 . On endoscopy, $89.1 \%$ of patients were diagnosed with UC, only 5 patients were diagnosed with Crohn's disease (10.9\%). The levels of agreement between the endoscopy results and the first and the second histopathology reports were poor and moderate with $\mathrm{k}$ coefficients of 0.265 and 0.491 , respectively. The level of aggrement between the first and the second histopatholoy reports was moderate ( $\mathrm{K}$ $=0.487$ ). Conclusion: The levels of aggrement between endoscopic results and histopathology results with and without expert opinion were low and medium $(\mathrm{\kappa}<0.6)$.

Keyword: Inflammatory bowel disease, IBD, histopathology, endoscopy.

\section{I. ĐăT VẤN ĐỀ}

Bênh viêm ruôt man tính (Inflammatory Bowel Disease - IBD) được đặc trưng bởi tình trạng viêm mạn tính của niêm mạc ruột với cơ chể bênh sinh khá phức tap trong đó có vai trò củamột số yễu tố đã được xác định như nhiễm khuẩn, yếu tố di truyền, di ứng và cơ chế tự miê̂n[1]. Theo một nghiên cứu phân tích gộp công bố năm 2017 dựa trên 147 nghiên cứu về IBD, tỷ lệ mắc bênh cao nhất được báo cáo ở Châu Âu và Bắc Mỹ. Từ năm 1990, tỷ lê mắc IBD đang tăng lên ở cả những nước đang phát triển, trong đó có châu Á[2]. Tuy nhiên có những vùng 